\title{
Forest fire impacts on buildings
}

\author{
E. Mikkola \\ Technical Research Centre of Finland, VTT, Finland
}

\begin{abstract}
Buildings and built areas may suffer from severe damage caused by forest and wild land fires. For the safety of people and the reduction of property losses it is important to be prepared by use of proper building construction and materials in potential areas of forest fires. This paper summarises the key factors to be taken into account when considering the impacts of forest fires on buildings: conditions caused by forest fires, impact mechanisms and the response of buildings and building materials.
\end{abstract}

Keywords: forest fire, buildings, ignition, heat transfer, simulation.

\section{Introduction}

Forest and wild land fires do not only burn down forests but also have serious impacts on buildings and infrastructures as well as endangering the safety of people. Many fires also occur in the wild land urban interfaces because human activities are the most common causes of forest fires.

In principle, there are three heat transfer mechanisms than can cause the ignition of buildings: radiation from the flames, convection of hot gases and spotting, i.e. transport of hot particles and firebrands. In an on-going project FIRE PARADOX [1] these mechanisms are being studied. These studies include, for example, the prediction of fire conditions at targets and the modelling of ignition or damage to building materials. Predictions of radiative heat fluxes and temperatures at target are being analysed as well as the transportation of firebrands. Key parameters are the fire front parameters (such as fire front height, depth and width, fire front intensity (MW/unit area)), distance to target, wind speed and target properties (such as materials exposed, openings/ventilation, etc.). 


\section{Forest fire intensities}

One of the most important boundary conditions in the analysis of fire effects on buildings is the intensity of the fire. A schematic view of the fire front and target situation is illustrated in Figure 1.

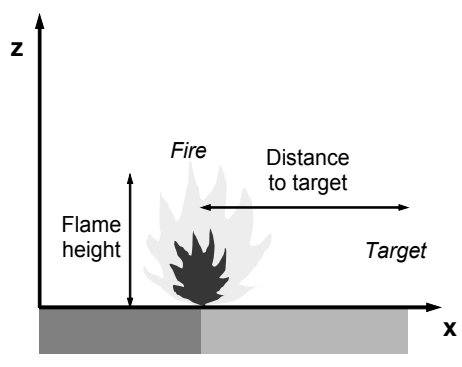

a) Side view

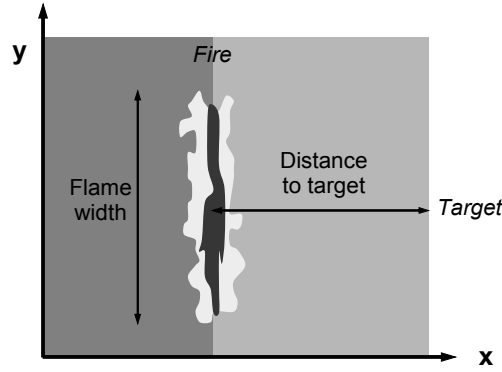

b) View from above

Figure 1: $\quad$ Schematic fire front - target (building) illustration.

Based on the literature data of forest fuel experiments, the following estimations of the maximum heat release rate per ground area given in Table 1 have been made. These heat release rate estimates are based on the mass loss data or oxygen consumption calorimetry. The values are given per square metre of ground area.

Table 1: $\quad$ Maximum heat release rate estimates for some forest fuels.

\begin{tabular}{|l|c|c|}
\hline Fuel type & $\begin{array}{l}\text { Maximum heat release } \\
\text { rate estimate }\left(\mathrm{MW} / \mathrm{m}^{2}\right)\end{array}$ & Reference \\
\hline Scotch pine $(2.3-3.1 \mathrm{~m}$ high) & $1.2-2.3$ & {$[2]$} \\
\hline Douglas fir trees $(2.1-4.5 \mathrm{~m}$ high) & $1.5-5.4$ & {$[3]$} \\
\hline $\begin{array}{l}\text { Pinus Pinaster (needles in wire- } \\
\text { mesh-basket) }\end{array}$ & $1.2-1.8$ & {$[4]$} \\
\hline Grass & 0.35 & {$[5]$} \\
\hline Feather moss (5 cm thick layer) & 0,25 & {$[6]$} \\
\hline
\end{tabular}

In practice, the highest heat release rate values per ground area for crown fires can be assumed to be described by the values of Scotch pine and Douglas fir trees of Table 1 giving an estimate form one to few $\mathrm{MW} / \mathrm{m}^{2}$. For bush and surface fires, the maximum heat release values are well below these values.

In analysing impacts to buildings from fire fronts passing by the exposure time also needs to be taken into account. For fast spreading surface fires the high impact may last less than one minute, but for major forest fires it can be tens of minutes. 
Spotting is also an important mechanism of wildland fire spread. Burning particles from forest fires can be carried by winds from few meters up to even kilometres from their source causing new starts of fires far from the original fire front.

\section{Impacts - methods for analysing heat transfer to buildings}

During the last few years computational fluid dynamics (CFD) simulations have been used to predict the spread of grass and forest fires (Larini et al. [7], Morvan and Dupuy [8,9], Mell et al. [3], Mell et al. [5]) and to calculate the effects of the fires on structures (Porterie et al. [10]).

Recently the effect of 2D assumption in calculations has been studied by performing a series of simulations in both two and three dimensions [11]. The simulations were performed using the Fire Dynamics Simulator (FDS) software [12], which is commonly used to simulate the fire phenomena both inside and outside buildings. FDS is well suited for the analysis of the current problem, which is based on the analysis of the heat fluxes from prescribed fire sources. The validity of 2D simulations was studied by running a series of simulations in both $2 \mathrm{D}$ and $3 \mathrm{D}$ at different boundary conditions. The differences between the 2D and 3D simulations were analysed by computing differences in convective and radiative heat fluxes and by averaging them over the heat release rate ranges of real forest fires (from surface fires to crown fires). The conclusion was drawn based the cases where significant heat fluxes at the target were found. The outcome was that 2D simulations can be used for order-of-magnitude type of analysis, for which purpose they are well suited due to the small computing times. However, the differences seem to be too large for accurate predictions of the building response. Therefore, the critical simulations of the impacts to target should be made in three dimensions [11].

Figure 2 below describes a simplified case where a forest fire front has reached a building and has caused ignition of a combustible facade of the building.

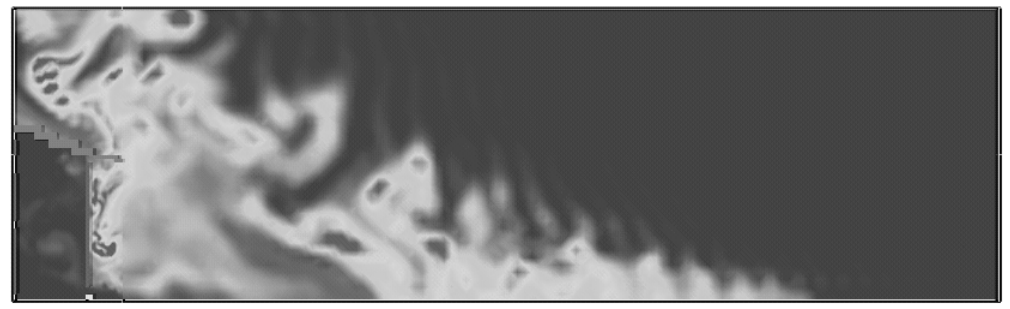

Figure 2: $\quad$ Side view of an ignited facade of a building (on the left) attacked by a forest fire. 
Firebrands can start new fires far from the original fire front. This makes it difficult to predict fire fronts movements. Several theoretical studies have been carried out on firebrand propagation with the aim to determine the maximum spotting distances for various kinds of firebrands in different ambient conditions. Experimental studies of firebrand spotting have been quite a few. The first studies of firebrand behaviour were conducted by Moreno et al. [13] who experimentally measured the mass loss rate and drag of particles of various shapes.

Many empirical burnings laws have been proposed for firebrands, but only a few more detailed models are found in the literature. In the works of Benkoussas et al. [14] and Sardoy et al. [15] a PDE (partial differential equation) model for thermal degradation of firebrands has been proposed.

Although advanced models of firebrand transport have recently been developed, the possibility of spotting can, at least to some extent, also be analyzed by assuming that the transport of hot particles is fully determined by the flow of gases. The existence of non-zero convective fluxes on the building surface is then an indicator of the impingement of the hot gas flow on the target, and correspondingly indicates a possibility of hot particles getting into contact with the target.

\section{Buildings - response to forest fire expose}

The response of building materials and structures to the exposure of forest fires can be described in most cases by the heating up of building materials, which results to break through of a construction. This beak through can occur either as a mechanical failure (materials such as concrete, metals, class) or after ignition as a burn through (materials which contribute to fire, such as timber, plastics) of the construction. Forest fires can spread to buildings also via openings (through ventilation channels, under eaves to attics, etc). This mode of fire spread is especially important in the case of firebrands.

Figure 3 illustrates the simplified heat transfer processes during the heatingup period of a material. Heat is transferred from the attacking fire to the surface of the material by radiation and convection. At the same time, there are heat losses from the surface by radiation and convection to the environment and heat is conducted to the inner parts of the material. If the total heat transfer from the fire is high enough, the surface temperature of the material will be raised to ignition limit. To calculate the ignition temperature, equations for heat transfer need to be solved.

A general model for the ignition of solid material has been presented by Mikkola and Wichman [16]. For thermally thick materials, the time to ignition is approximately

$$
t_{i g}=\rho c k\left(\frac{T_{i g}-T_{0}}{\dot{q}_{\text {in }}^{\prime \prime}-\dot{q}_{\text {out }}^{\prime \prime}}\right)^{2}
$$

and for thermally thin materials the time to ignition is approximately 


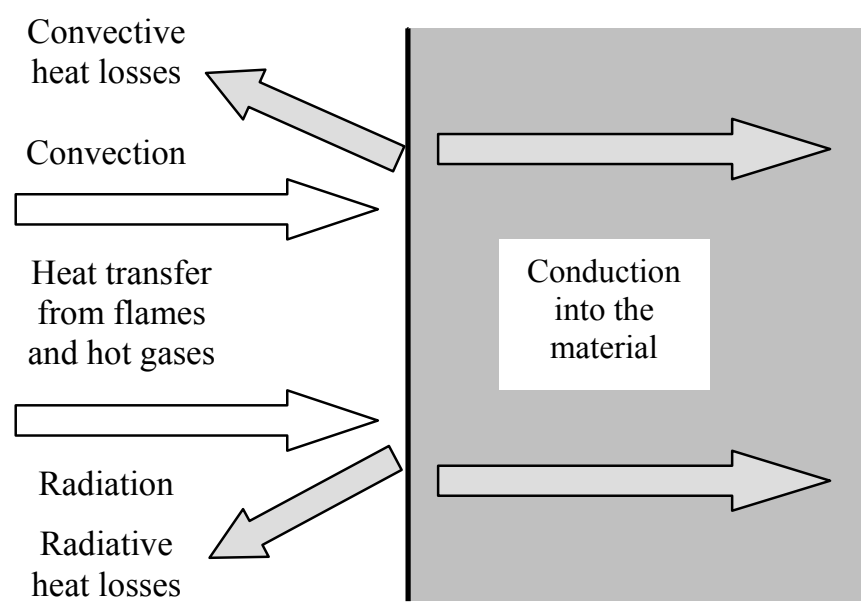

Figure 3: $\quad$ Simplified heat transfer processes during the heating up of a solid material.

$$
t_{i g}=\rho c L \frac{T_{i g}-T_{0}}{\dot{q}_{i n}^{\prime \prime}-\dot{q}_{o u t}^{\prime \prime}}
$$

where

- $\quad \rho, c$ and $k$ are the density, specific heat and thermal conductivity of the material, respectively,

- $L$ is the thickness of the material,

- $T_{i g}$ is the ignition temperature,

- $T_{0}$ is the ambient temperature,

- $\quad \dot{q}_{i n}^{\prime \prime}$ is the imposed heat flux and

- $\quad \dot{q}_{\text {out }}^{\prime \prime}$ is the heat loss term (both radiant and convective) from the surface of the material to the surroundings.

An important feature of the model is that it distinguishes between thermally thick and thermally thin materials. Thermally thick materials have a relatively low thermal conductivity, which means that they only heat up within a thin layer near the surface of the material prior to ignition. Thermally thin materials have a relatively high thermal conductivity, which means that they heat up thoroughly prior to ignition. It should be noted, however, that the question of whether a material is thermally thick or thin depends not only on the thermal conductivity of the material but also on the magnitude of the applied heat flux and on the thickness of the material.

Values of thermal properties (density, specific heat and thermal conductivity) of building materials can be easily found from text books. Piloted (=small flame, spark, etc. available to ignite pyrolysis gases) ignition temperature values for most materials are between 270 and $450{ }^{\circ} \mathrm{C}$. 
Based on the equations (1) and (2) and plotting experimental results of $\boldsymbol{t}_{\text {ig }}{ }^{-1 / 2}$ (thermally thick) or $\boldsymbol{t}_{i g}{ }^{-1}$ (thermally thin) as a function of $\dot{q}_{i n}^{\prime \prime}$, critical heat fluxes for piloted ignition can be defined. Examples of reported critical heat fluxes are [16]: Wood products $10-13 \mathrm{~kW} / \mathrm{m}^{2}$, PVC $9 \mathrm{~kW} / \mathrm{m}^{2}$, polyurethane $4 \mathrm{~kW} / \mathrm{m}^{2}$ and PMMA below $5 \mathrm{~kW} / \mathrm{m}^{2}$.

Time to ignition in equations (1) and (2) can also be interpreted as time to failure for materials that do not ignite but will have for instance a mechanical failure at a certain temperature. For this purpose the temperature for ignition in the equations (1) and (2) should then be interpreted as a temperature for failure (specific for the material and failure type).

\section{Conclusions}

To estimate potential damages forest fires can cause to buildings it is essential to know the intensities of fires and exposes to buildings as well as the different fire spread mechanisms. Large areas of external walls and roofs attacked by heat and firebrands should be made of materials not contributing to fire development in potential forest fire areas. Additionally protective means to prevent breaking of windows, to prevent spread of firebrands to ventilation systems and to attics need to be realized.

The response of building materials and products to fire can be described by thermal models. Coupling these models with simulations of fire conditions and defining criteria for failures of building constructions under forest fire exposes still need further research to be carried out.

\section{Acknowledgements}

The co-operation of Simo Hostikka, Johan Mangs and Topi Sikanen within the FIRE PARADOX project in providing background data for this paper is gratefully acknowledged. This paper was partly supported by the European Commission under the $6^{\text {th }}$ Framework Programme through the Integrated Project FIRE PARADOX (contract no. FP6018505).

\section{References}

[1] FIRE PARADOX, An Innovative Approach of Integrated Wildland Fire Management - Regulating the Wildfire Problem by the Wise Use of Fire: Solving the Fire Paradox, www.fireparadox.org/index.php

[2] Stroup, D. W. DeLauter, L. A. Lee, J. H. \& Roadarmel, G. L. Scotch Pine Christmas Tree Fire Tests. Gaithersburg: NIST: Report of Test. FR 4010. 28 p. 1999. http://www.fire.nist.gov/bfrlpubs/fire00/PDF/f00147.pdf

[3] Mell, W.E., Manzello, S.L. \& Maranghides A. Numerical Modeling of Fire Spread through Trees and Shrubs. D. X. Viegas (Ed.), V International Conference on Forest Fire Research, 2006. 
[4] Dupuy, J. L., Marechal, J. \& Morvan, D. Fires from a cylindrical forest fuel burner: combustion dynamics and flame properties. Combustion and Flame, 135, pp. 65-76, 2003.

[5] Mell, W.E., Jenkins, M.A., Gould, J. and Cheney, P. A Physics-Based Approach to Modelling Grassland Fires. International Journal of Wildland Fire, 16, pp. 1-22, 2007.

[6] FIRE PARADOX, Cone Calorimeter results of forest fuels, VTT 2008 (to be published).

[7] Larini, M., Giroud, F., Porterie, B. and Loraud, J. -C. A multiphase formulation for fire propagation in heterogeneous combustible media, International Journal of Heat and Mass Transfer, 41, pp. 881-897, 1998.

[8] Morvan, D., Dupuy, J.L. Modeling of Fire Spread Through a Forest Fuel Bed Using a Multiphase Formulation. Combustion and Flame, 127, pp. 1981-1994, 2001.

[9] Morvan, D., Dupuy, J.L. Modeling the propagation of a wildfire through a Mediterranean shrub using a multiphase formulation. Combustion and Flame, 138, pp. 199-210, 2004.

[10] Porterie, B. Consalvi, J.-L., Loraud, J.-C., Giroud, F. and Picard, C. Dynamics of wildland fires and their impact on structures, Combustion and Flame, 149, pp. 314-328, 2007.

[11] Hostikka, S., Mangs, J., Mikkola, E. Comparison of two and three dimensional simulations of fires at wildland urban interface. Proceedings of the 9th IAFSS Symposium. 21-26 September 2008, Karlsruhe, Germany. International Association for Fire Safety Science, 2008 (to be published).

[12] McGrattan, K. B., Hostikka, S., Floyd, J. E., Baum, H. \& Rehm, R. Fire Dynamics Simulator (Version 5): Technical Reference Guide. NIST SP 1018-5. NIST Special Publication 1018-5. October 2007. Building and Fire Research Laboratory. National Institute of Standards and Technology, 2007.

[13] Moreno, F.G., Villa, A.R., Tarifa, C.S. \& Del Notario, P.P. Transport and combustion of firebrands, reports of grants fg-sp-114 and fg-sp-146. Technical report, U.S. Dept of Agriculture Forest Service, 1967.

[14] Benkoussas, B., Consalvi, J.L., Porterie, B., Sardoy, N. and Loraud, J.C. Modelling thermal degradation of woody fuel particles. International Journal of Thermal Sciences, 46(4), 319-327, 2007.

[15] Sardoy, N., Consalvi, J.-L., Porterie, B. and Fernandez-Pello, A.C. Modeling transport and combustion of firebrands from burning trees, Combustion and Flame, 8, pp. 151-169, 2007.

[16] Mikkola, E. and Wichman, I.S. On the thermal ignition of combustible materials. Fire and Materials, 14, pp. 87-96, 1989. 